\title{
A Reconsideration Of The Locational Advantages Of Transshipment Points
}

\author{
RICHARD RAYMOND*
}

The literature in location theory repeatedly emphasizes the advantages possessed by sites located at breaks in a transportation system. Many of the world's largest and most prosperous cities are located in such positions; and it is implied, if not explicitly stated, that their prosperity is due to the fact that they are transshipment points. An unqualified acceptance of this view may lend support to questionable policy alternatives. Transshipment points may be selected as optimal sites for the concentration of development efforts even though more attractive alternatives exist. An exaggeration of the impact of a transshipment point upon economic activity may also serve to overshadow other relevant aspects surrounding public decisions to create or expand transportation facilities.

The observed tendency for processing facilities to locate at transshipment points has frequently been treated in a vague and misleading manner in both the professional literature and in textbook expositions. Textbooks generally explain the tendency of plants to locate at transshipment points in very simple terms: "Costs are involved transferring goods from one form of transport to another, and these costs can be evaded by locating a plant at the break in the transportation network." 1 In his recent text, Hoover argues that such statements are quite misleading. ${ }^{2}$ He supports this contention by carefully examining a specific hypothetical situation in which the material and product are assumed to have equal weights and equal transport costs. ${ }^{3}$ He correctly demonstrates that under these conditions the transshipment point cannot enjoy an advantage in transport costs over both the market and the materials source. ${ }^{4}$ A review of recent texts indicates that Hoover's conclusions have not yet been completely accepted. Heilbrun's discussion of transshipment points is, for instance, essentially the same as that contained in older works. ${ }^{5}$

An earlier investigation by Alonso contained a graphical analysis of the situation examined by Hoover. ${ }^{6}$ Alonso also noted that under the conditions implied by his analysis, the transshipment point did not have a transport cost advantage over the market or the materials source. Unlike Hoover, however, Alonso implied that this result emanated from the special conditions or assumptions which he had incorporated into

\footnotetext{
*Professor of Economics, Research Associate, Center for Urban Regionalism and Environmental Systems. The author acknowledges helpful comments from Michael Sesnowitz and Kristofer Neslund.
} 
his analysis. Alonso concluded by noting that circumstances are frequently such that the transshipment point does enjoy a transport cost advantage over the other two potential sites. No arguments or data were presented in support of this conclusion.

The purpose of this paper is to clarify the nature of the locational advantages which have led to the clustering of manufacturing and processing activity at transshipment points. The first section demonstrates that there are conditions, albeit unlikely ones, which are capable of generating a transport cost advantage for the transshipment point. Section II explores the role of scale and agglomeration economies in production. Section III contains a discussion of some dynamic aspects of the problem and the final section briefly examines some implications of the analysis.

\section{I.) Transport Cost Advantage - Three Point Case}

The confusion emanating from the apparent contradiction between the Hoover and Alonso analyses may be removed with a detailed examination of a simple three location example. To facilitate the exposition, it will be assumed that water transport connects the material source and the transshipment point and that rail transport connects the transshipment point with the market. The transport cost situation may be described symbolically with the aid of the following terms:

$\mathrm{L}_{\mathrm{wm}}=$ cost of loading (or unloading) one ton of raw material on boat

$\mathrm{R}_{\mathrm{wm}}=$ cost/mile of transporting one ton of raw material by water

$\mathrm{L}_{\mathrm{rm}}=$ cost of loading (or unloading) one ton of raw material on train

$\mathrm{R}_{\mathrm{rm}}=\mathrm{cost} / \mathrm{mile}$ of transporting one ton of raw material by rail

$\mathrm{L}_{\mathrm{wp}}=$ cost of loading (or unloading) one ton of the final product on boat

$\mathrm{R}_{\mathrm{wp}}=\operatorname{cost} /$ mile of transporting one ton of the final product by water

$\mathrm{L}_{\mathrm{rp}}=$ cost of loading (or unloading) one ton of the final product on train

$R_{\mathrm{rp}}=$ cost/mile of transporting one ton of the final product by rail

$\mathrm{D}_{\mathrm{sm}}=$ distance from the material source to the market (by way of the transshipment point)

$\mathrm{D}_{\mathrm{st}}=$ distance from the material source to the transshipment point

$\mathrm{D}_{\mathrm{tm}}=$ distance from the transshipment point to the market

$\mathrm{G}=$ number of tons of the raw material needed to produce one ton of the final product

The transport costs associated with the location of processing facilities at the material source, transshipment point and market are given by the following expressions:

(1) material source

$$
\begin{array}{ll}
\text { (1) material source } & 2 \cdot \mathrm{L}_{\mathrm{wp}}+\mathrm{R}_{\mathrm{wp}} \cdot \mathrm{D}_{\mathrm{st}}+2 \cdot \mathrm{L}_{\mathrm{rp}}+\mathrm{R}_{\mathrm{rp}} \cdot \mathrm{D}_{\mathrm{tm}} \\
\text { (2) transshipment point } & 2 \cdot \mathrm{G} \cdot \mathrm{L}_{\mathrm{wm}}+\mathrm{G} \cdot \mathrm{R}_{\mathrm{wm}} \cdot \mathrm{D}_{\mathrm{st}}+2 \cdot \mathrm{L}_{\mathrm{rp}}+\mathrm{R}_{\mathrm{rp}} \cdot \mathrm{D}_{\mathrm{tm}} \\
\text { (3) market } & 2 \cdot \mathrm{G} \cdot \mathrm{L}_{\mathrm{wm}}+\mathrm{G} \cdot \mathrm{R}_{\mathrm{wm}} \cdot \mathrm{D}_{\mathrm{st}}+2 \mathrm{G} \cdot \mathrm{L}_{\mathrm{rm}}+\mathrm{G}^{\cdot} \mathrm{R}_{\mathrm{rm}} \cdot \mathrm{D}_{\mathrm{tm}}
\end{array}
$$$$
\text { (3) market }
$$

Thus, if the transshipment point is to represent a better processing location than the material source, the following must hold: 


$$
2 \cdot \mathrm{G} \cdot \mathrm{L}_{\mathrm{wm}}+\mathrm{G} \cdot \mathrm{R}_{\mathrm{wm}} \cdot \mathrm{D}_{\mathrm{st}}<2 \cdot \mathrm{L}_{\mathrm{wp}}+\mathrm{R}_{\mathrm{wp}} \cdot \mathrm{D}_{\mathrm{st}}
$$

This simply states that from the material source to the transshipment point, the cost of shipping the raw material necessary to produce the product must be less than the cost of shipping the product.

Similarly, if the transshipment point is to represent a better location for processing than the market, the following must hold:

$$
2 \cdot \mathrm{L}_{\mathrm{rp}}+\mathrm{R}_{\mathrm{rp}} \cdot \mathrm{D}_{\mathrm{tm}}<2^{\bullet} \mathrm{G}^{\bullet} \mathrm{L}_{\mathrm{rm}}+\mathrm{G} \cdot \mathrm{R}_{\mathrm{rm}} \cdot \mathrm{D}_{\mathrm{tm}}
$$

This means that from the transshipment point to the market, the cost of shipping the product must be less than the cost of shipping the raw material necessary to make the product. Processing will, therefore, take place at the transshipment point only if inequalities (4) and (5) are simulataneously satisfied.

The conditions considered by Hoover and Alonso imply that $\mathrm{L}_{\mathrm{wm}}=-\mathrm{L}_{\mathrm{wp}}$, $\mathrm{L}_{\mathrm{rm}}=\mathrm{L}_{\mathrm{rp}}, \mathrm{R}_{\mathrm{wm}}=\mathrm{R}_{\mathrm{wp}}, \mathrm{R}_{\mathrm{rm}}=\mathrm{R}_{\mathrm{rp}}$ and $\mathrm{G}=1$. When the appropriate substitutions are made in (4) and (5), the inequalities change to equalities. Under these conditions, then, the transshipment point does not have a transport cost advantage over either the material source or the market. ${ }^{7}$ This is, however, a special case. In general, two offsetting factors will be at work: (i) the final product may weigh somewhat less than the raw material used in its production and (ii) the freight rate may be somewhat higher for the finished product than for the raw material. These factors clearly work in opposite directions. A relatively large weight loss creates an incentive to transport the final product rather than the raw material, whereas a large difference in freight rates favoring the raw material tends to tip the balance toward transporting the raw material rather than the finished product. Inequalities (4) and (5) will both be satisfied and therefore the selection of the transshipment point will minimize transport expense if the cost of transporting the raw material is less than the cost of transporting the finished product from the material source to the transshipment point while, at the same time, the opposite is true for a movement from the transshipment point to the market. This unlikely state of affairs is rendered possible by the change of mode at the transshipment point. $^{8}$

Hoover has advanced a further argument against the potential transport cost advantage of the transshipment point. He observes that the unloading plus loading (terminal) costs at the transshipment point should be higher if processing occurs at this site. ${ }^{9}$ It should be cheaper to transfer either the raw material or the product directly from the boat to the train than to move the raw material from the boat to the processing plant and then the product from the plant to the train. But this only demonstrates that the terminal costs at the transshipment point are likely to be lower if the good being transported does not change form at that point. To complete the picture, the terminal costs at all stages in the shipment process must be considered. Processing at the materials source, for instance, does not effect a savings by reducing the number 
of times the goods must be handled. In either case, the raw material must be taken from a conveyance, moved to the processing plant and the product must be moved from the plant back onto another conveyance. The same conclusion holds when processing at the market site is considered. It appears unlikely, therefore, that the transshipment point is at a major disadvantage because of larger terminal costs. ${ }^{10}$

\section{II.) Scale and Agglomeration Economies}

Since the circumstances leading to a pure transport cost advantage for transshipment points appear somewhat improbable, other explanations of the importance of these locations as processing sites must be considered. One such explanation, scale and agglomeration effects in processing or production, seems to have been overlooked in the literature. ${ }^{11}$

The simple 3-location analysis (material source - transshipment point - market) is undoubtedly misleading. There may be a number of material sources all shipping to the same transshipment point which in turn ships to a number of different markets. The location problem in this case can be broken down into a series of the simple 3-site problems as long as both the individual material sources and the individual markets are sufficient in size to exhaust any scale and agglomeration economies that may exist in the production process. But if this is not the case, then a number of material sources or a number of markets will have to be combined to realize the cost reductions associated with scale and agglomeration effects. When this occurs, the transshipment point has a natural advantage which is illustrated in Figure 1.

Assume that grain from sources a, b, c, d, and e must be collected at a single milling site in order to exhaust scale and agglomeration economies. Milling may be undertaken at either the transshipment point, $t$,

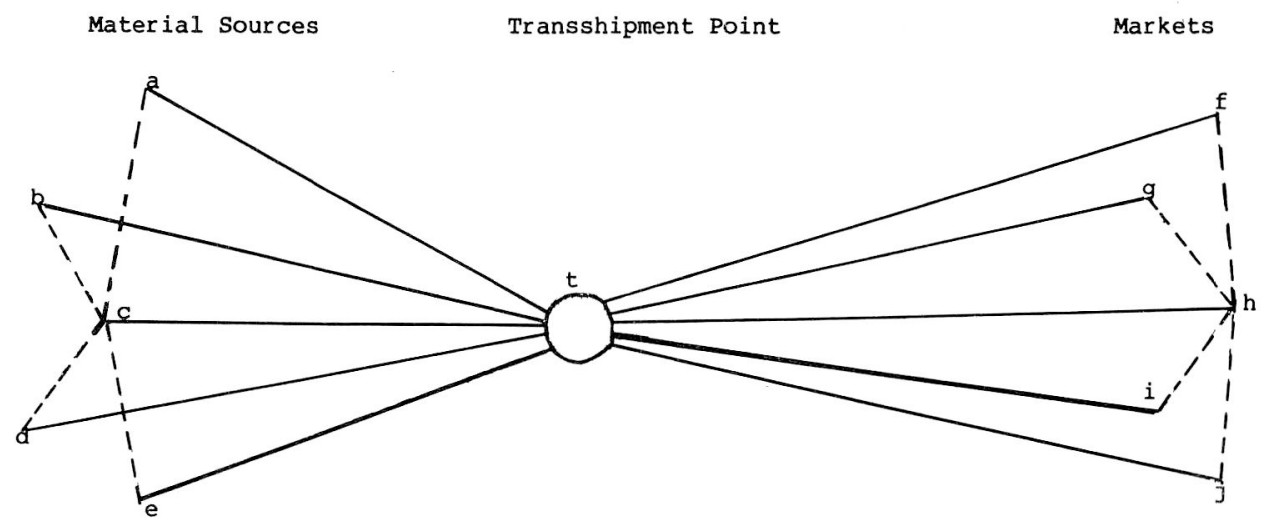


or the most advantageously located grain source, e.g., point c. Milling costs are, by assumption, the same at point $t$ and point $\mathrm{c}$.

If a single transport rate applies to both grain and flour, and if processing generates no weight change, then total transport costs associated with milling at $t$ will equal the transport rate $(R)$ multiplied by the following expression:

(6)

$$
Q_{a} \cdot D_{a t}+Q_{b} \cdot D_{b t}+Q_{c} \cdot D_{c t}+Q_{d} \cdot D_{d t}+Q_{e} \cdot D_{\text {et }}
$$

where $Q_{a} \ldots Q_{e}$ are the amounts of grain produced at a . . e, respectively, and $D_{\mathrm{at}} \ldots \mathrm{D}_{\mathrm{et}}$ are the distances between the material sources and the transshipment point. Similarly, if milling takes place at $c$, then total shipment transport costs will equal $\mathrm{R}$ multiplied by:

(7)

$\mathrm{Q}_{\mathrm{a}}\left(\mathrm{D}_{\mathrm{ac}}+\mathrm{D}_{\mathrm{ct}}\right)+\mathrm{Q}_{\mathrm{b}}\left(\mathrm{D}_{\mathrm{bc}}+\mathrm{D}_{\mathrm{ct}}\right)+\mathrm{Q}_{\mathrm{c}} \cdot \mathrm{D}_{\mathrm{ct}}+\mathrm{Q}_{\mathrm{d}}\left(\mathrm{D}_{\mathrm{dc}}+\mathrm{D}_{\mathrm{ct}}\right)+\mathrm{Q}_{\mathrm{e}}\left(\mathrm{D}_{\mathrm{ec}}+\mathrm{D}_{\mathrm{ct}}\right)$

The following inequalities will hold unless all of the material sources fall on a ray passing through $t$ :

$$
\mathrm{D}_{\mathrm{ac}}+\mathrm{D}_{\mathrm{ct}}>\mathrm{D}_{\mathrm{at}} ; \mathrm{D}_{\mathrm{bc}}+\mathrm{D}_{\mathrm{ct}}>\mathrm{D}_{\mathrm{bt}} ; \mathrm{D}_{\mathrm{dc}}+\mathrm{D}_{\mathrm{ct}}>\mathrm{D}_{\mathrm{dt}} ; \mathrm{D}_{\mathrm{ec}}+\mathrm{D}_{\mathrm{ct}}>\mathrm{D}_{\mathrm{et}}
$$

Thus, the transport costs associated with milling at a material source must be greater than the transport costs incurred if milling takes place at the transshipment point.

There are two conditions capable of reversing this conclusion. In the case of multiple material sources, transport costs might actually be lowered by going through a centrally located source if each individual source did not generate enough raw material to exhaust the economies of scale in transportation. If this were to prove true, then the raw material would flow through the centrally located source in any event and the choice between this source and the transshipment point would hinge upon the weight change associated with processing and the difference in freight rates between the raw material and the final product. Second, if the transport rate per unit of product were sufficiently lower than the transport rate for the material necessary to produce a unit of product, then the material source would prove to be the best processing site. This condition is analagous to the situation leading to the choice of the material source in a simple two location analysis. In the present case, however, location at the material source requires that the lower transport cost for the final product be sufficient to more than offset the extra cost involved in consolidating the raw material at the centrally located source. The same analysis may be applied, mutatis mutandis, to the choice between the transshipment point and a centrally located market site.

\section{III.) Dynamic Considerations}

The factors determining the most desirable location at a given moment may obviously change with the passage of time. Consider a case in which 
scale and agglomeration economies render the transshipment point the most advantageous location for processing facilities during the early stages of an area's development. Subsequent growth in the size of either individual material sources or markets may negate this advantage thereby changing, from a static point of view, the optimal location for processing facilities. ${ }^{12}$ It may, however, be economically inadvisable to relocate processing facilities under these circumstances. The physical capital already in place at the transshipment point must be appropriately weighted when relocation is considered. The disadvantages now associated with location at the transshipment point may be more than offset by the losses necessitated by the sale or scrapping of specialized physical equipment.

This problem or complication is not necessarily temporary in nature. If all of the physical capital in place at the transshipment point were constructed at the same time, then there might be a single optimal replacement time for all of these facilities. ${ }^{13}$ Ultimately, this would put the location decision back on the planning board and the static model would again be applicable. But the transshipment point may harbor many different vintages of capital, each of which should be replaced at a different point in time. This may make it difficult or impossible for individual firms to move and still benefit from agglomeration economies. ${ }^{14}$

Processing facilities may therefore continue to locate at the transshipment point after the advantages originally dictating this location are no longer present. The unique patterns of historical development in the industry may make a change in location inadvisable for firms acting on an individual basis. It is thus necessary when examining location patterns to consider the current situation in conjunction with the conditions prevailing over a number of past time periods.

\section{IV.) Summary and Implications}

Conventional wisdom relating to transshipment points is often accepted without critical scrutiny. The advantages of transshipment points as processing sites are automatically assumed to exist simply because of the many examples of extensive industrial development at such locations. The preceeding analysis suggests that the growth of transshipment points may initially have been the result of scale economies in production and that their continued pre-eminence may be due to the persistence of the agglomeration economies generated by extensive industrial development. Changing technology in both production and transportation coupled with increases in population and its concentration is capable of significantly altering the advantages enjoyed by transshipment points. Thus a tendency simplistically to apply past experience to present situations could give rise to seriously misleading conclusions and recommendations.

This has recently been illustrated in the case of airport facilities for the newly developed supersonic jets. Any community housing an airport is, to a certain extent, in the position of a transshipment point. This posi- 
tion is accentuated for facilities capable of handling the largest jets which are economically best suited to provide international service since only a limited number of such facilities are planned for the nation. Publicity surrounding the attempts of local communities to gain public support for the construction of such facilities frequently exhibits an unquestioning acceptance of the economic benefits accruing to a transshipment point. In one form or another, the classical argument relating rapid ecozornic development to the existence of a break in the transportation network finds its way into the public debate. This occurs in spite of the almost complete lack of empirical evidence relating the existence of airport facilities to industrial development. ${ }^{15}$

Before the beneficial effects of these new transshipment points can legitimately be made the basis for public policy decisions, a much more careful examination of their alleged economic impact must be undertaken. It is not at all clear that the factors which led to the economic growth of transshipment points in the past are present in the same form and to a significant degree in this newest example of a break in the transportation network.

A similar caveat appears to be in order in the case of planning efforts designed to stimulate industrial activity both in the poorer regions of advanced countries and in the underdeveloped nations of the world. The casiest course of action for the planners is simply to accept the "natural advantages" offered by transshipment points. But the only way to determine if a transshipment point is the best location for an industrial complex is through a complete examination of all alternative sites. Failure to do this could result in very costly errors.

\section{FOOTNOTES}

${ }^{1}$ Harry W. Richardson, Regional Economics. Praeger Publishers, New York, 1969, p. 45. See also Hugh O. Nourse, Regional Economics, McGraw-Hill Book Company, 1968, p. 79.

2Edgar M. Hoover, An Introduction to Regional Economics. Alfred A. Knopf, New York, 1971, p. 53.

In his earlier work on location theory, Hoover argued that a transshipment point was most likely to be a preferred processing location "if transport costs on material and product are nearly equal ..." and if "the weight of the 'material' is about the same as that of the 'product'. . ." Edgar M. Hoover, The Location of Economic Activity. McGraw-Hill, 1948, paperback edition, 1976, p. 40.

4 Hoover then proceeds to enumerate a number of other factors capable of explaining the observed tendency for processing facilities to locate at transshipment points. The factors are (1) the transport advantages of junction points, (2) "scale economies in transfer and terminal operations, . . .", (3) existence of "specialized facilities for goods handling and storage," and (4) the fact that "many modes of transfer serve only a limited set of points along their routes." Hoover, op. cit., "An Introduction to
Regional Economics," pp. 54-55, emphasis mine.

5James Heilbrun, Urban Economics and Public Policy. St. Martin's Press, New York, 1974, p. 65.

6William Alonso, "Location Theory," in John Friedman and William Alonso eds., Regional Development and Planning. The M.I.T. Press, Cambridge, Mass. 1964, pp. 86-88. The assumptions underlying Alonso's analysis are not explicitly stated but they appear to be equivalent to those employed by Hoover.

iFurthermore, as Alonso's analysis correctly points out, under these condtions it is also impossible for either the material source or the market to enjoy a tranport cost advantage. See Ibid.

$8 \mathrm{~A}$ necessary but not a sufficient condition for the transshipment point to gain a transport cost advantage over both the material source and the market is that the difference between the product and raw material freight rates be greater for the mode in use between the material source and the transshipment point than for the mode connecting the transshipment point and the market. This condition is not sufficient to ensure a universal advantage for 
the transshipment point since a large weight loss in processing could still render the material source the point of lowest transport cost. If this condition does hold, then from the point of view of transport costs alone, the market is effectively eliminated as a processing site.

9 Edgar M. Hoover, An Introduction to Regional Economics, pp. 53-54.

10 The frequency of handling might be reduced in the case of a point source of raw material production. This could occur if the point source generated a suffcient volume of the raw material to justify locating the processing facility precisely at the raw material source. This might occur in the case of a mine or a well. When processing takes place at the market site, the frequency of handling can only be reduced if distribution emanates from a sufficiently large storage facility which can be located at the processing site.

${ }_{11}$ Scale economies in transport operations have been examined. See Hoover, An Introduction to Regional Economies, p. 54.

12The impact of growth in the size of material sources or markets may, of course, be either accentuated or mitigated by technological change.

${ }_{13}$ This assumes that all capital depreciates at the same rate.

${ }_{14} \mathrm{~A}$ major technological breakthrough would eliminate this problem if it rendered all existing capital obsolete at the same time.

15The Greater Cleveland Growth Association (GCGA) has claimed that the establishment of a jetport in Northeast Ohio will create 30,000 new jobs in an "air-oriented industrial and research park, a national import-export center and a freeport." Undated pamphlet circulated by the GCGA "A New Approach to the Cleveland/Northeastern Ohio Region." The Lake Erie International Jetport Project." Yet consultants examining the potential impact of the proposed jetport have pointed out that a study of 27 major airports showed that in only 3 cases was there "considerable development with much of it attributable to airport generated activity." Howard, Needles, Tammen and Bergendoff, Land Site Investigations: Impacts Analysis and Recommendations, for second phase Airport Feasibility Study for the Lake Erie Regional Transportation Authority, p. 105. The citation given for the quote is Real Estate Research Corporation, Chicago Airport Site Selection Study: An Analysis of Some of the Major Considerations, Chicago: City of Chicago, 1968. 